\title{
Enhancing Student Altruism Using Secure Attachment Messages (SAM) in Lecture
}

\author{
Kelly Campbell \\ California State University, San Bernardino \\ Kelly@csusb.edu \\ Stephany Ramos \\ California State University, San Bernardino
}

\begin{abstract}
In this brief report, we examine whether students' $(N=230)$ willingness to help individuals in distress (altruism) would be augmented after viewing Secure Attachment Messages (SAM) during lecture in a college racism course. Students were presented with SAM in alternating weeks as part of the PowerPoint presentation slides. In each of the weeks, their likelihood of engaging in altruistic behaviors was assessed using hypothetical scenarios and a student response system, Top Hat Monocle. We predicted that the SAM would prompt students to think of their attachment figures and enhance their feelings of security, which would increase their willingness to engage in altruistic behaviors. Our hypothesis was statistically supported in that students reported greater altruism towards individuals of various ethnic backgrounds on days for which SAM were shown in lecture. The results suggest that SAM may promote prosocial tendencies, particularly in courses with sensitive subject matter.
\end{abstract}

Keywords: attachment theory, altruism, teaching, race, ethnicity, racism, Top Hat Monocle

According to attachment theory, individuals have styles of relating to people based on the type of care they receive as children (Cassidy \& Shaver, 2016). Those who receive warm, responsive, and consistent care develop secure styles and are able to form deep, trusting bonds in their adult relationships. Those who receive inconsistent or neglectful care tend to develop insecure attachment styles. As adults, these individuals are fearful, needy, and distrustful of others. Securely attached individuals experience better outcomes in a variety of contexts. They have healthier and happier relationships with romantic partners, friends, and acquaintances (Zayas, Mischel, Shoda, \& Aber, 2011; Zeifman \& Hazan, 2016). They also have higher self-esteem, are more motivated, open to criticism, and engage in more prosocial behaviors (Mikulincer \& Shaver, 2016a). Our study extended the literature on attachment theory by applying its propositions in a classroom setting. Specifically, we examined whether students in a university Race and Racism course would report greater altruism after viewing Secure Attachment Messages (SAM) in lecture compared to days when SAM were not shown.

Researchers have identified three primary attachment styles: Secure, anxious/ambivalent, and avoidant (Cassidy, 2016). A secure style develops when an infant receives consistent, high quality care from their parent or primary caregiver. Secure children learn that people are trustworthy, dependable, and competent. As such, they feel comfortable relying on them for need 
fulfillment. When distressed, they seek comfort from significant others and provide support to people in need of care. Approximately 50-60\% of the adult population has a secure attachment style (Bakermans-Kranenburg \& van IJzendoorn, 2009). These individuals experience positive outcomes in their individual development (e.g., confidence, achievement) and interpersonal relationships (Mikulincer \& Shaver, 2016a; Zeifman \& Hazan, 2016).

When an infant is exposed to care that is inconsistent, they develop an anxious/ambivalent attachment style (Cassidy, 2016). Through the caregiving relationship, they learn that people are unpredictably available. Given that anxious/ambivalent individuals do not receive adequate care in early childhood, they are not fully comfortable or satisfied within the caregiving relationship. Anxious ambivalent adults are clingy towards significant others; they pursue closeness, yet due to their insecurities about losing these connections, they seek excessive attention and become jealous when individuals do not meet their demands (Feeney, 2016). These tendencies cause people to withdraw from the relationship. As such, the anxious/ambivalent schema--that close others are unreliably available for need fulfillment--is reinforced. Approximately $20 \%$ of the adult population has an anxious/ambivalent attachment style (Bakermans-Kranenburg \& van IJzendoorn, 2009).

Infants who receive little to no attention from their primary caregivers develop an avoidant attachment style (Cassidy, 2016). These children learn that people cannot be depended upon during times of need. When distressed, they display signs of detachment towards their primary caregiver. For example, they do not make eye contact or engage in proximity seeking behaviors. As adults, avoidant individuals steer away from intimate relationships, either from fear of abandonment (fearful subtype) or because they prefer to meet their own needs, independent of others (dismissive subtype). Individuals with this style find it difficult to trust or depend on people (Feeney, 2016). Approximately $20-30 \%$ of the adult population has an avoidant attachment style (BakermansKranenburg \& van IJzendoorn, 2009).

Attachment styles generally remain stable over time because interpersonal expectations are reconfirmed through self-fulfilling prophecies (Fraley, 2002; Konrath, Chopik, Hsing, \& O’Brien, 2014). If a person has developed a belief that others cannot be relied upon (avoidant style), they will be aloof in their interactions, which discourages further contact. The person's existing schema is therefore reconfirmed through a series of interactions over the lifespan. Given that attachment styles are socialized, change is possible when a new relationship challenges the established orientation. In such cases, a person may switch from one style to another or develop complex schemas (e.g., secure with women, avoidant with men).

A person's attachment style predicts their responses to a variety of situations, including threatening and dangerous encounters. Compared to those with insecure attachments, the securely attached are more prone to comfort and help people in need, even when the person is a stranger (Richman, DeWall, \& Wolff, 2015). In one study, participants watched a woman partake in tasks such as holding a lab rat, putting hands in ice cold water, and touching a live tarantula (Mikulincer, Shaver, Gillath \& Nitzberg, 2005). The researchers assessed participants' willingness to help the woman in order to relieve her anxiety. Results indicated that the securely attached were more likely than the insecurely attached to offer assistance (Mikulincer et al., 2005). This study provided initial support for the association between attachment style and altruism. When individuals feel supported and secure, they are more likely to help those in need. This propensity is learned from the responsive care they received as children and from modeling their secure caregivers' behaviors (Cassidy, 2016; Feeney, 2016).

Attachment insecurity can hinder the caregiving system by interfering with the emotions of empathy and compassion (Mikulincer \& Shaver, 2016b). Insecurely attached individuals have 
a tendency to fulfill their own needs when faced with danger. They lack the innate caregiving response to stressful situations (Richman et al., 2015). However, when insecurely attached individuals are relieved of threat or suffering, they are better able to focus attention on others and engage in acts of altruism (Mikulincer et al., 2005). The present study will examine altruism in the context of racism. Altruism is an important variable in this milieu because low empathy is a predictor of prejudice (McFarland, 2010), above and beyond the effects of stable attributes such as personality (Bergh, \& Akrami, 2016).

In a landmark study, Mikulincer and Shaver (2001) explored whether attachment priming could be used to alter behavioral responses for people with different attachment styles. They specifically assessed whether secure prompts might reduce biases toward out-group membersdefined as those who do not match a person's own ethnic background — and increase the likelihood of helping out-group members in distress (altruism). The participants were recruited from an Israeli university and consisted of Jewish and Arab individuals. They were shown subliminal words on a computer screen that included Secure Attachment Messages (SAM) such as love and support. The researchers found that regardless of the participant's established attachment style, priming a secure schema reduced their negative responses toward out-group members. They were able to empathetically feel concern for a person in distress, regardless of their ethnic background.

Based on attachment theory and the reported empirical findings, we hypothesized that university students enrolled in a Race and Racism course would report enhanced altruism if primed with SAM. We expected these results irrespective of their pre-existing attachment schema because prior work has demonstrated the positive effects of secure priming for individuals across styles (e.g., Carnelley, Otway, \& Rowe, 2016; Mikulincer \& Shaver, 2001; Tang, Chen, Hu \& Liu, 2017). The Race and Racism course was selected because it contains controversial material that triggers feelings of threat related to ethnicity (Maher \& Tetreault, 1997). These feelings may be especially pronounced for students with insecure (i.e., anxious ambivalent, avoidant) attachment styles (Vaughn, Battle, Taylor, \& Dearman, 2009). To our knowledge, scholars have yet to apply the attachment framework to study issues such as racism in a college classroom setting. A majority of the published literature in this area addresses student reactions to learning about racism (e.g., Boatright-Horowitz, Marraccini, \& Harps-Logan, 2012) or strategies to reduce racism (e.g., Vera, Camacho, Polanin, \& Salgado, 2016). However, the topic is worthy of study because of its implications for reducing anxiety and augmenting prosocial tendencies in stressful college courses. Our study therefore fills an important knowledge gap.

\section{Method}

\section{Participants}

Data were collected from 280 students enrolled in an upper division university Race and Racism course. Students who were missing 2 data points or more were not included in the analyses, resulting in a final sample of 230 students. The IRB did not permit the collection of specific demographic data because participants were enrolled in the principle investigator's course and might feel coerced to participate if identifiers were known. However, the professor had access to data through the course roster indicating that the students represented majors from each of the campus colleges (i.e., Arts and Letters, Business, Education, Natural Science, Social Science). They also reflected the general university population in terms of gender (approximately 60\% women) and ethnicity (approximately 40\% Latina/o, 20\% European/White, 20\% Hawaiian/Pacific

Journal of the Scholarship of Teaching and Learning, Vol. 17, No. 4, October 2017. josotl.indiana.edu 
Islander, 10\% African American/Black, and 10\% Asian, mixed, Native American, or other). Participants were treated in accordance with the Ethical Principles of Psychologists and Code of Conduct (American Psychological Association, 2010).

\section{Procedure}

Before participating in the study, students were provided with an informed consent document that was distributed as part of the course syllabus. They were informed that their responses would be collected anonymously using a student response system and kept confidential. If they did not wish to participate in the study, they did not need to inform the professor of their decision; they were simply asked not to repond to the research questions posed in class (see below).

The instructor used PowerPoint slides for each of her lectures during a 10-week quarter. Data were not collected during the first or last week of class, which resulted in eight weeks of assessment. The class met twice a week for two hours each time. In alternating weeks, the professor presented Secure Attachment Message (SAM) slides between the regular content slides. The SAM slides were displayed for 5 seconds and contained images and words pertaining to love, comfort, and security (see below). The goals of SAM were to strengthen students' feelings of security, reduce perceptions of threat, and thereby encourage altruism. To assess altruism, the professor presented students with hypothetical scenarios (see below) at the end of each class session and asked them to rate the likelihood of helping the targets in need. Students recorded their responses using Top Hat Monocle, which is a student response system that is accessed through personal devices such as cell phones, tablets, and laptop computers. All recorded responses were stored on Top Hat Monocle's website and downloaded by the instructor at the end of the quarter. The analytic strategy involved comparing students' average altruism scores for weeks that SAM were shown to average altruism scores for weeks that SAM were not shown.

\section{Materials}

Secure Attachment Messages (SAM). In order to prompt students with SAM, the professor developed PowerPoint slides displaying words such as love, acceptance, and comfort and images relating to love and security (e.g., family members embracing). The content for SAM was modeled after Mikulincer and Shaver's (2001) attachment prompts. The slides were designed to reflect a variety of caregiving relationships. Given that some students may have insecure relationships with parents, images of siblings, friends, and intimate partners were also displayed.

Altruism. Students' likelihood of engaging in altruistic behaviors was assessed using hypothetical scenarios and data were collected via the Top Hat Monocle feedback tool. The scenarios were written by the professor and described situations that students might encounter on campus. Each scenario was presented with a photograph of a student in distress. The photographs included individuals from a variety of ethnic backgrounds. A sample scenario included, "As you leave class today, this student approaches you, explains they were unable to attend class, and asks if you would lend them your notes. What is the likelihood of you complying with the student's request?" The response options were: 0\% (no chance), 25\%, 50\% (possibly), 75\%, and 100\% (absolutely). When the scenarios were displayed on the screen, the professor read the descriptions aloud. Participants' responses were immediately recorded using their personal devices (e.g., cell phones) and stored 
on the Top Hat Monocle website. Students who did not have a personal device were offered a payas-you-go cell phone, which covered the cost of texting their responses throughout the quarter.

\section{Results}

Table 1 displays the students' mean altruism scores across the eight-week assessment period. A paired samples t-test was used to compare mean altruism scores for the weeks that SAM were shown versus not shown in class. The significance level was set at .05. Our hypothesis was supported. We found that students reported greater altruism for weeks in which SAM were shown $(\mathrm{M}=69.16, \mathrm{SD}=17.56)$ compared to weeks they were not shown $(\mathrm{M}=58.02, \mathrm{SD}=18.86) ; \mathrm{t}(229)$ $=4.19, \mathrm{p} \leq .001 ; d=.61$. The effect size $(d=.61)$ corresponded with Cohen's (1988) standard for a medium $(d=.50)$ to large effect $(d=.80)$.

Table 1. Mean altruism scores for eight-week assessment period

\begin{tabular}{ccc}
\hline Week & Secure Attachment Messages Shown & Mean Altruism Score \\
\hline 1 & Yes & 73.74 \\
2 & No & 64.91 \\
3 & Yes & 58.11 \\
4 & No & 61.40 \\
5 & Yes & 60.58 \\
6 & No & 40.35 \\
7 & Yes & 47.98 \\
8 & No & 59.76 \\
\hline
\end{tabular}

\section{Discussion}

The purpose of this study was to investigate whether students would report greater altruism when prompted with Secure Attachment Messages (SAM) in lecture. Prior empirical work has demonstrated that compared to individuals with insecure attachment styles (i.e., anxious ambivalent, avoidant), those with a secure style engage in more selfless and prosocial behaviors (Mikulincer \& Shaver, 2016; Zeifman \& Hazan, 2016). Mikulincer and Shaver (2001) additionally found that secure priming encouraged altruism in an ethnically divided setting (i.e., an Israeli university attended by Arab and Jewish students), even for individuals with insecure styles. Their findings were important to the present investigation because we implemented the same strategy in an ethnically diverse U.S. context. Although a variety of factors could arguably ease tension and reduce insecurity in a racism course, we focused on attachment because of its demonstrated positive impact on factors such as self-esteem, academics, and relationships (Cassidy \& Shaver, 2016). Our hypothesis was supported and provided additional evidence for the benefits of secure attachment priming.

Based on our results, we recommend that SAM be incorporated into college courses, especially those that elicit anxiety such as race relations or statistics (e.g., Dykeman, 2011). Professors can remind students to think of a bond with a significant other when they experience stress during a class discussion, assignment, or exam. Additional applications could involve encouraging actual prosocial behaviors among students rather than having students imagine hypothetical scenarios. After displaying SAM, students could turn to a neighbor and offer Journal of the Scholarship of Teaching and Learning, Vol. 17, No. 4, October 2017.

josotl.indiana.edu 
assistance with lecture notes that were missed or help classmates work through a difficult concept. Professors might also prompt students to engage in community service outside of the classroom, particularly because volunteerism is a known predictor of academic achievement and positive well-being (Beattie, Laliberte, \& Oreopoulos, 2016; Martela \& Ryan, 2016).

In moving forward, researchers might examine the effects of SAM at other education levels including elementary, middle, and high school. At the elementary level, SAM might be used to help children overcome separation anxiety, particularly when entering the school system for the first time. The transition to school is often difficult because children must adapt to a new environment without their primary caregiver(s) (Seven, 2010). In such situations, SAM could be employed to enhance children's secure feelings and reduce perceptions of threat. Teachers could display SAM in the classroom (e.g., pictures of students with their primary caregivers) and encourage children to play with attachment related toys (e.g., a teddy bear brought from home). Parents might additionally incorporate elements of the classroom into their home environment to bridge the two settings.

At the intermediate and high school levels, SAM might be used to reduce bullying or violent acts between students. When insecurely attached individuals are relieved of danger or distress through mechanisms such as SAM, their empathy and altruism propensities are enhanced (Mikulincer et al., 2005). To this end, a variety of activities might be used to prompt students with SAM and remind them of their support systems. Assignments such as journaling or projects that focus on friendship building could be implemented. Teachers might incorporate SAM-inspired meditations or media into their classes. Students could also create photo collages displaying people with whom they have secure bonds (e.g., family, peers, mentors), and post collages to their desks or in notebooks. These strategies might reduce the desire to act on impulses that lead to maladaptive behaviors such as bullying.

Aside from attachment, it is important to note that students may experience discomfort or insecurity in a racism course for a variety of reasons. Differences in social power related to gender, age, socioeconomic status (SES), ability level, sexual orientation, and religion might contribute to differential outcomes in educational and social settings (Anderson \& Middleton, 2010). The first author has been teaching courses on racism for the past 10 years and noted that students feel strongly attached to aspects of their identities associated with pain or for which they have experienced discrimination. A European American/white man who has experienced oppression related to SES for example, might have difficulty accepting his racial privilege. As such, students may feel threatened by course material that seems to contradict their lived experiences. The professor advises her students to reflect on the totality of their identities, identify those that are privileged versus not, and recognize how oppression pertaining to one status may cause resistance to the race-related content. Although it was beyond the scope of the present study to examine the multitude of factors influencing feelings of threat in a classroom setting, we nonetheless wish to acknowledge that attachment style is only one of these factors and hope future work will investigate other contributors.

As with any research, our study contained strengths and limitations. One benefit relates to the use of Top Hat Monocle; this tool enabled us to gather immediate feedback regarding the effects of SAM. Top Hat Monocle was also effective in that students used their own devices (e.g., cell phones, laptops) to input data, which eliminated the hassle of paper collection, enabled the data to be accurately and conveniently stored in a database (thereby eliminating researcher input error), and also provided students with the ability to respond anonymously. The anonymity

Journal of the Scholarship of Teaching and Learning, Vol. 17, No. 4, October 2017. josotl.indiana.edu 
afforded by the response system was important given the sensitive nature of the course material and the threat of social desirable response bias that exists with other methods.

In terms of limitations, we used hypothetical scenarios to assess altruism, rather than actual behaviors. Future researchers might address this concern by having confederates act out scenes in class that would afford students the opportunity to help. Sample scenarios could include a student (confederate) dropping their belongings or asking a classmate for assistance with note taking or a course assignment. We were also limited by ethical considerations that prohibited the collection of demographic data. Access to such information would have allowed for more precise comparisons. For example, how might altruism differ for targets who are perceived as in- versus out-group members?

Future work should assess the effects of SAM on a variety of academic outcomes including learning. The goal of SAM is to alleviate stress and enhance security, conditions which are known to enhance comprehension (Turner, Bartlett, Andiappan, \& Cabot, 2015). Researchers might examine whether SAM exposure improves test scores, for example. In such cases, teachers can display SAM immediately before an exam (i.e., short-term exposure) as well as throughout the semester or academic year to examine long-term effects. The opportunities for extending the results of our study are plentiful and we hope our work will inspire continued research and applications in this area.

\section{References}

American Psychological Association (2010). Publication manual of the American Psychological Association (6 $6^{\text {th }}$ ed.). Washington, DC: American Psychological Association.

Anderson, S. K., \& Middleton, V. A. (2010). Explorations in diversity: Examining privilege and oppression in a multicultural society ( $2^{\text {nd }} \mathrm{ed}$.). Belmont, CA: Brooks/Cole.

Bakermans-Kranenburg, M. J., \& van IJzendoorn, M. H. (2009). The first 10,000 adult attachment interviews: Distributions of adult attachment representations in clinical and non clinical groups. Attachment \& Human Development, 11(3), 223-263.

https://doi.org/10.1080/14616730902814762

Beattie, G., Laliberte, J. P., \& Oreopoulos, P. (2016). Thrivers and divers: Using non-academic measures to predict college success and failure. National Bureau of Economic Research. https://doi.org/10.3386/w22629

Bergh, R., \& Akrami, N. (2016). Are non-agreeable individuals prejudiced? Comparing different conceptualizations of agreeableness. Personality And Individual Differences, 101153-159. https://doi.org/10.1016/j.paid.2016.05.052

Boatright-Horowitz, S. L., Marraccini, M. E., \& Harps-Logan, Y. (2012). Teaching antiracism: College students' emotional and cognitive reactions to learning about white privilege. Journal Of Black Studies, 43(8), 893-911. https://doi.org/10.1177/0021934712463235

Carnelley, K. B., Otway, L. J., \& Rowe, A. C. (2016). The effects of attachment priming on Journal of the Scholarship of Teaching and Learning, Vol. 17, No. 4, October 2017. josotl.indiana.edu 
depressed and anxious mood. Clinical Psychological Science, 4(3), 433-450.

https://doi.org/10.1177/2167702615594998

Cassidy, J. (2016). The nature of the child's ties. In J. Cassidy \& P. R. Shaver (Eds.), Handbook of attachment ( $3^{\text {rd }}$ ed.) (pp. 3-24). New York: Guilford Press.

https://doi.org/10.1080/0092623X.2017.1317533

Cassidy, J. \& Shaver, P. R. (2016). Handbook of attachment: Theory, research, and clinical applications. New York: Guilford Press. https://doi.org/10.1080/0092623X.2017.1317533

Cohen, J. (1988). Statistical power analysis for the behavioral sciences (2nd ed.). Hillsdale, NJ: Lawrence Erlbaum Associates.

Dykeman, B. F. (2011). Statistics anxiety: Antecedents and instructional interventions. Education, 132(2), 441-446.

Feeney, J. A. (2016). Adult romantic attachment: Developments in the study. In J. Cassidy \& P. R. Shaver (Eds.), Handbook of attachment ( $3^{\text {rd }}$ ed.) (pp. 435-463). New York: Guilford Press. https://doi.org/10.1080/0092623X.2017.1317533

Fraley, R. C. (2002). Attachment stability from infancy to adulthood: Meta-analysis and dynamic modeling of developmental mechanisms. Personality and Social Psychology Review, 6, 123-151. https://doi.org/10.1207/S15327957PSPR0602_03

Konrath, S. H., Chopik, W. J., Hsing, C. K., \& O'Brien, E. (2014). Changes in adult attachment styles in American college students over time: A meta-analysis. Personality and Social Psychology Review, 18(4), 326-348. https://doi.org/10.1177/1088868314530516

Maher, F. A., \& Tetreault, M. T. (1997). Learning in the dark: How assumptions of Whiteness shape classroom knowledge. Harvard Educational Review, 67(2), 321-349.

https://doi.org/10.17763/haer.67.2.j7866368086k9491

Martela, F., \& Ryan, R. M. (2016). The benefits of benevolence: Basic psychological needs, beneficence, and the enhancement of well-being. Journal Of Personality, 84(6), 750-764. https://doi.org/10.1111/jopy.12215

McFarland, S. (2010). Authoritarianism, social dominance, and other roots of generalized prejudice. Political Psychology, 31(3), 453-477. https://doi.org/10.1111/j.14679221.2010.00765.x

Mikulincer, M. \& Shaver, P. R. (2001). Attachment theory and intergroup bias: Evidence that priming the secure base schema attenuates negative reactions to out-groups. Journal of Personality and Social Psychology, 81(1), 97-115. https://doi.org/10.1037//0022-3514.81.1.97

Mikulincer, M. \& Shaver, P. R. (2016a). Adult attachment and emotion regulation. In J. Cassidy \& P. R. Shaver (Eds.), Handbook of attachment ( $3^{\text {rd }}$ ed.) (pp. 507-533). New York: Guilford

Journal of the Scholarship of Teaching and Learning, Vol. 17, No. 4, October 2017.

josotl.indiana.edu 
Press. https://doi.org/10.1080/0092623X.2017.1317533

Mikulincer, M. \& Shaver, P. R. (2016b). Attachment in adulthood: Structure, dynamics, and change ( $2^{\text {nd }}$ ed.). New York. NY: The Guilford Press.

Mikulincer, M., Shaver, P. R., Gillath, O., \& Nitzberg, R. A. (2005). Attachment, caregiving, and altruism: Boosting attachment security increases compassion and helping. Journal of Personality and Social Psychology, 89(5), 817-839. https://doi.org/10.1037/0022-3514.89.5.817

Richman, S. B., DeWall, C. N., \& Wolff, M. N. (2015). Avoiding affection, avoiding altruism: Why is avoidant attachment related to less helping? Personality and Individual Differences, 76, 193-197. https://doi.org/10.1016/j.paid.2014.12.018

Seven, S. (2010). Attachment and social behaviors in the period of transition from preschool to first grade. Social Behavior and Personality: An international journal, 38, 347-356. https://doi.org/10.2224/sbp.2010.38.3.347

Tang, Q., Chen, X., Hu, J., \& Liu, Y. (2017). Priming the secure attachment schema affects the emotional face processing bias in attachment anxiety: An fMRI research. Frontiers in Psychology, 8, 1-12. https://doi.org/10.3389/fpsyg.2017.00624

Turner, J., Bartlett, D., Andiappan, M., \& Cabot, L. (2015). Students' perceived stress and perception of barriers to effective study: impact on academic performance in examinations. British Dental Journal, 219(9), 453-458. https://doi.org/10.1038/sj.bdj.2015.850

Vaughn, L. M., Battle, J. V., Taylor, T., \& Dearman, L. (2009). Learning styles and the relationship to attachment styles and psychological symptoms in college women. College Student Journal, 43(3), 723-735.

Vera, E., Camacho, D., Polanin, M., \& Salgado, M. (2016). Education interventions for reducing racism. In A. N. Alvarez, C. H. Liang, H. A. Neville, A. N. Alvarez, C. H. Liang, H. A. Neville (Eds.), The cost of racism for people of color: Contextualizing experiences of discrimination (pp. 295-316). Washington, DC, US: American Psychological Association. https://doi.org/ $\underline{10.1037 / 14852-000}$

Zayas, V., Mischel, W., Shoda, Y., \& Aber, J. L. (2011). Roots of adult attachment: Maternal caregiving at 18 months predicts adult peer and partner attachment. Social Psychological And Personality Science, 2(3), 289-297. https://doi.org/10.1177/1948550610389822

Zeifman, D. M. \& Hazan, C. (2016). Pair bonds as attachments: Mounting evidence in support of Bowlby's hypothesis. In J. Cassidy \& P. R. Shaver (Eds.), Handbook of attachment ( $3^{\text {rd }}$ ed.) (pp. 416-434). New York: Guilford Press. https://doi.org/10.1080/0092623X.2017.1317533 